\title{
CONGENITAL AORTIC SEPTAL DEFECT
}

BY

\author{
J. H. DADDS AND CLIFFORD HOYLE
}

From King's College Hospital and St. Helier Hospital

Received May 16, 1949

A defect in the wall of the ascending aorta leading to free communication with the adjacent pulmonary artery is a rare congenital abnormality. The opening in the anterior wall of the aorta is just above the semilunar cusps and leads directly into the pulmonary artery. Maude Abbott (1927) regarded it as a partial defect of the aortic septum, probably at the point where the distal bulbar swellings meet the aortic septum and above the junction of the aortic and interventricular septa. A commoner form of communication is between an aortic sinus and either the conus of the right ventricle (Abbott, 1919; Brown, 1939) or the right auricle (Goehring, 1920; Macleod, 1944), usually due to a ruptured congenital aneurysm of a sinus of Valsalva. Abbott (1937) also described a third rarer variety where a small hole in the aortic wall, just above the valves leads into the conus by an oblique channel. Here the aortic valves are usually bicuspid. An example of this type of abnormality was described by Rickards (1881).

This report concerns an example of the first of these anomalies, an example of value chiefly because there were no other congenital defects. The various features, clinical and pathological, to which the aortic septal patency had led, formed a combined picture of the pure defect that is rarely seen and therefore worth recording.

\section{CASE RePort}

A boy of 14 came under observation about two years before he died, when admitted to Horton Emergency Hospital in May 1943 for increasing dyspnœa on exertion and for palpitation. He had been breathless from infancy, and his activities had been severely curtailed since early childhood, though latterly he had done a light office job near his home. He had been prone to recurrent bronchitis and more recently to severe epistaxes.

He was a pale stunted youth with a kyphotic chest, the anterior wall of which bulged forward prominently on the left side. Cardiac pulsation was diffuse and thrusting, with the impulse maximal in the seventh space $16 \mathrm{~cm}$. to the left of the midline. The beat was regular at a resting rate of 80 a minute. A diastolic thrill was easily palpable just inside the cardiac impulse and also to the left of the sternum at the base. A systolic and a diastolic murmur were heard all over the præcordia, the latter generally louder and more impressive and best heard in the pulmonary area and just internal to the impulse. The systolic element, loudest in the aortic area where it overshadowed the other, was well conducted to the root of the neck on each side. Both heart sounds were audible in all areas, and the pulmonary second sound was accentuated. The blood pressure was $130 / 40$ and the pulse collapsing. Neither cyanosis nor clubbing were present, nor had he any congestive failure. Other systems were normal.

Radioscopy showed a huge aneurysmal shadow comprising the pulmonary artery and aorta astride the greatly enlarged heart (Fig. 1). The aortic component was normally sited but very pulsatile, and no separate aortic knuckle could be seen. In oblique views the ascending aorta was prominent, and a barium swallow showed a combined aortopulmonary impression. Both ventricles were very large, the right larger than the left, and the right auricle was also thought to be moderately enlarged. The left auricle was flat in the right (I) oblique position (Fig. 2), but the pulmonary artery radicles were all prominent and there was a marked hilar dance. Apart from their enlarged vessels the lung fields were normal. An electrocardiogram showed a rather low voltage $\mathrm{R}$ I, high $\mathrm{R}$ II and R III and a diphasic $\mathrm{T} I$, but was otherwise unremarkable (Fig. 3).

After keeping fairly fit and at work until October 1944 he then began to have recurrent faints and increasing breathlessness, for which he was readmitted the following January. He was still pale, but now moderately cyanosed as well, though he 


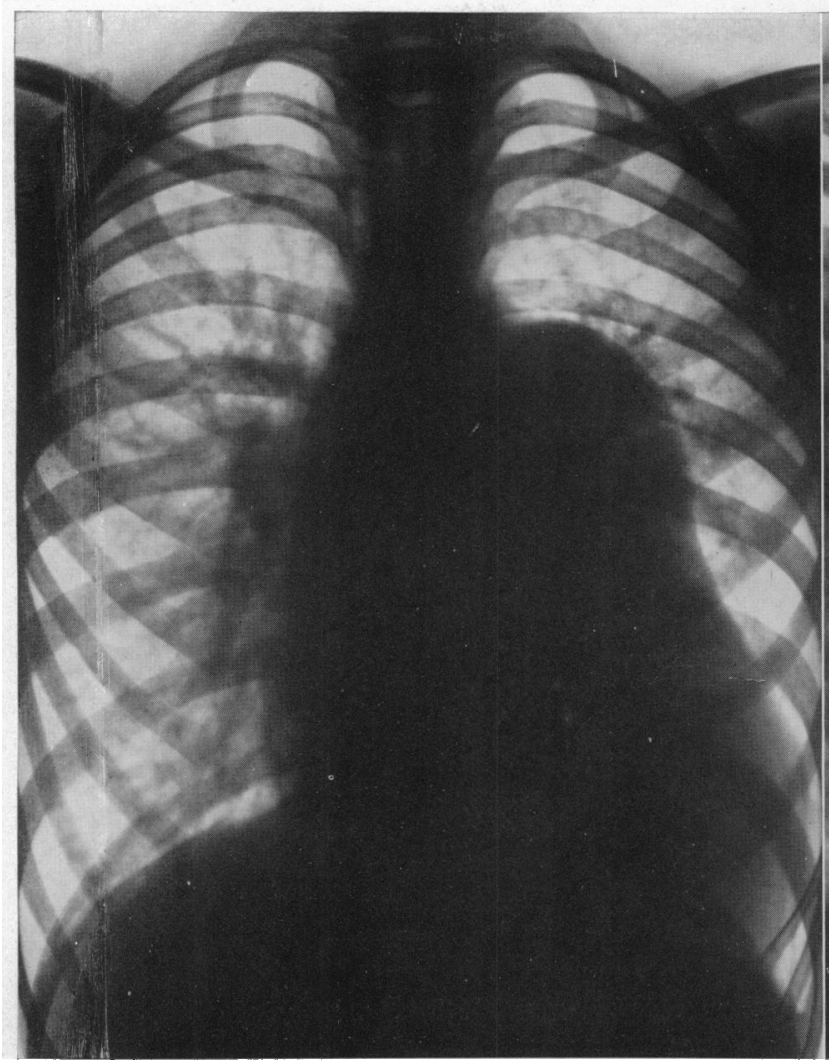

FIG. 1.-Radiograph (anterior view) showing aortopulmonary sac, enlarged pulmonary vessels and enlarged ventricles. $26 / 5 / 43$.

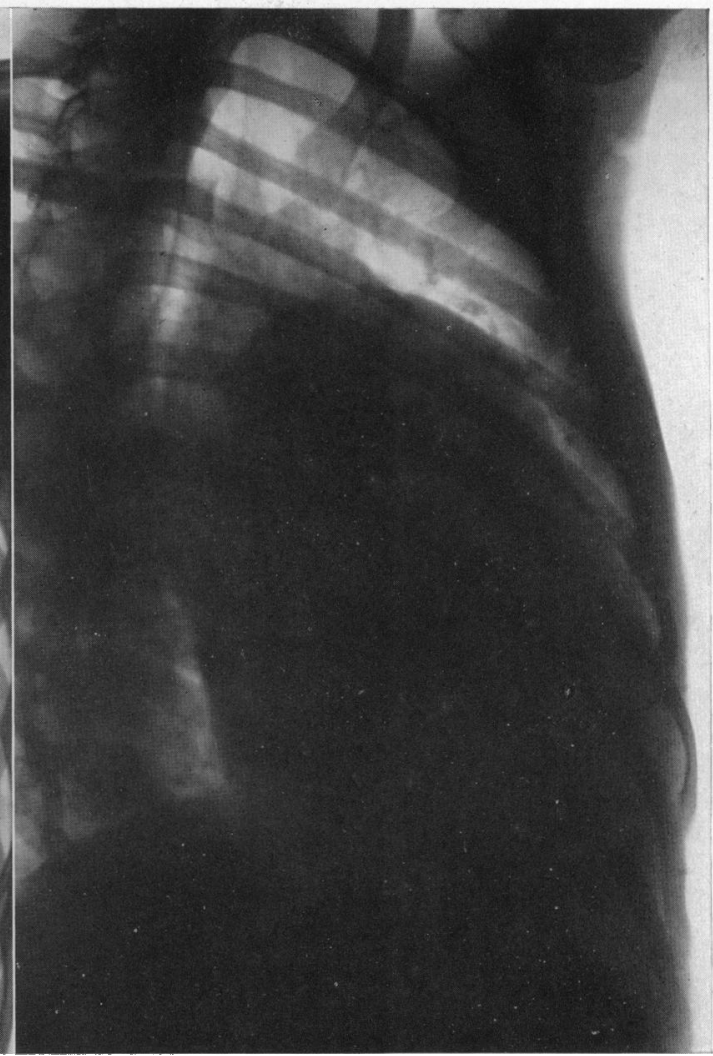

FIG. 2.-Radiograph (right (I) oblique view) showing aorto-pulmonary sac and aortic arch above it, enlarged right ventricle and flat left auricle.

had a normal blood count. There was no congestion and his cardiovascular signs were unaltered except that the heart's action was more forceful and further enlargement of the aneurysmal sac and of both ventricles was evident radiologically (Fig. 4). $\mathrm{He}$ had repeated nose bleeds and also, from time to time, severe sweating attacks which were quite unexplained. There was no evidence of endocarditis or other infective process. He improved gradually with rest and was convalescent by March.

He was admitted for the last time seven months later in congestive heart failure. He had fallen ill a week before with catarrhal symptoms and was already in a grave state when admitted, orthopnœic, moderately cyanosed, and sweating profusely, though afebrile. The neck veins were much engorged, the liver enlarged, tender and pulsating, and there was dependent œdema. The left chest wall bulged even more than before and the action of the heart shook the whole thorax. The murmurs were unaltered except that the diastolic murmur was more obtrusive and now loudest in the mitral area. The

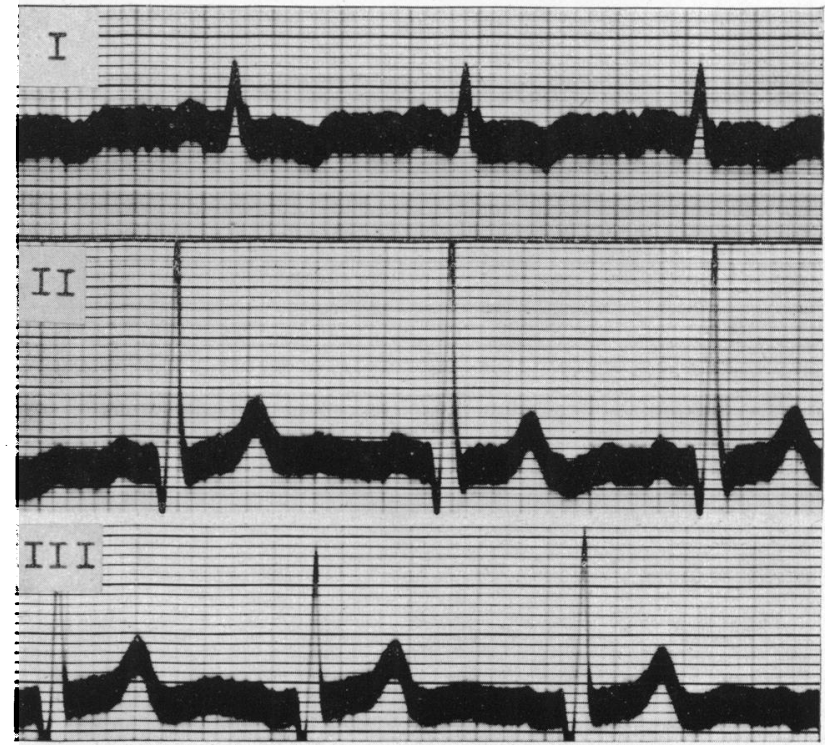

FIG. 3.-Electrocardiogram. 


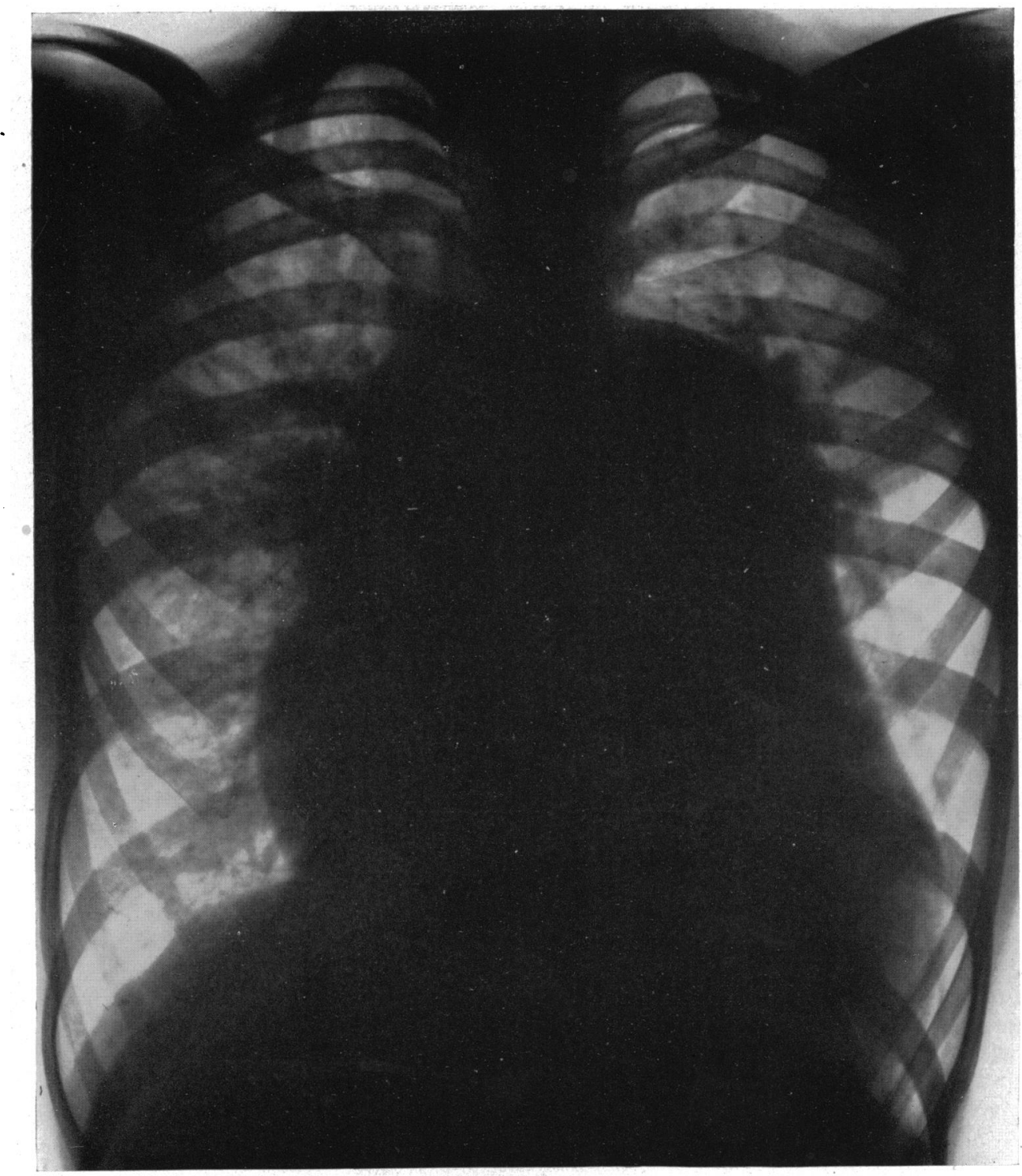

FIG. 4.-Radiograph (anterior view) showing further enlargement of aorto-pulmonary sac and heart, also more engorgement of lung vessels. 22/4/44. The maximum transverse diameter is now 18 $\mathrm{cm}$. in a chest of $24.5 \mathrm{~cm}$. instead of $16 / 23.5 \mathrm{~cm}$. in 1943 (Fig. 1).

pulmonary second sound was very loud. Rest, sedatives, and diuretics failed to give relief and he died suddenly a few days later.

\section{NECROPSY REPORT}

The body was well nourished but undersized. Both lungs were congested and there was excess of straw-coloured fluid in the pleural sacs and about
$350 \mathrm{ml}$. in the pericardium. The liver was enlarged and intensely congested.

In situ the heart was surmounted by a large aneurysmal sac comprising the main pulmonary artery and the contiguous aorta (Fig. 5). The heart weighed $390 \mathrm{~g}$. and was greatly enlarged. Both ventricles were much hypertrophied and dilated, the right ventricle particularly. Their walls were of equal thickness, measuring $2.0 \mathrm{~cm}$. across. In 


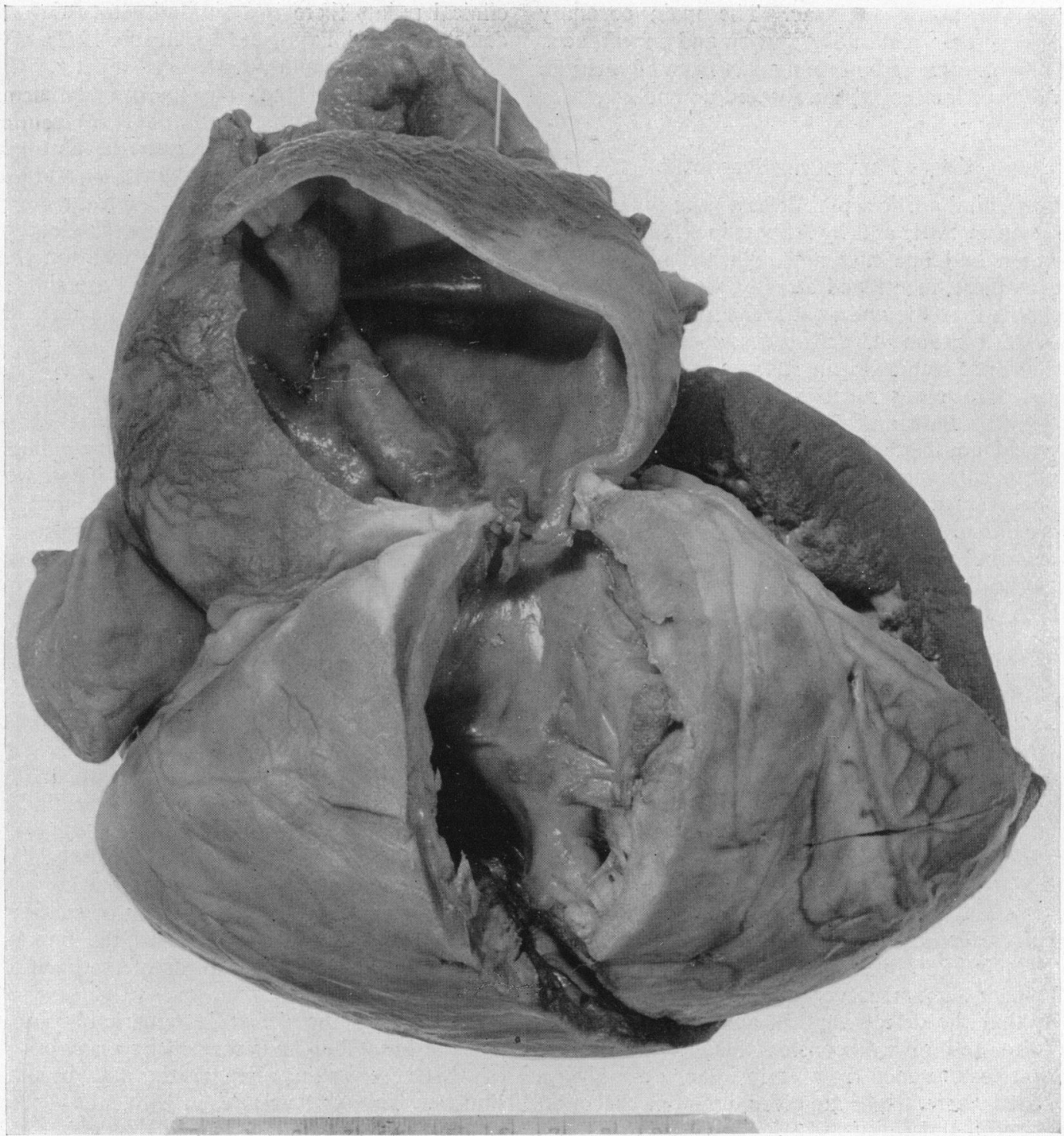

FIG. 5.-Necropsy specimen, anterior view, showing the aneurysmal sac.

contrast the auricles were not enlarged. All the heart valves were normal, but the mitral ring took three fingers easily. The interauricular and interventricular septa were normal.

The aneurysmal sac when opened showed a wide communication between the hugely dilated pulmonary artery and the base of the aorta, just above the valves. The defect measured 6.0 by $5.0 \mathrm{~cm}$. Its edges were quite smooth, and a small septal ridge formed its lower border between the aortic. and pulmonary valves. The valve cusps were all normally sited. The size of the defect was such that it gave an appearance of both ventricles opening through their respective valves into a common sac from which the right and left pulmonary arteries arose above and posteriorly, and the aorta above, anteriorly and to the right. The aorta itself was markedly hypoplastic, measuring $4.1 \mathrm{~cm}$. in circumference at the top of the arch. There was no coarctation; the innominate, left common carotid and left subclavian arteries were normally sited; and the fibrosed cord of the ductus was identified 
above the aneurysmal sac. The main coronary vessels were normal in distribution and appearance.

Other organs were normal apart from congestion. Sections of the lung tissue showed no endarteritis.

\section{Cases Previously Reported}

Congenital aortic septal defects were reviewed by Hektoen in 1901, and by Abbott in 1927 and 1937. Hektoen had one case and collected nine others; one of these, mentioned already, was described by Rickards in 1881, and as it seems to belong to the rare third group of defect described by Abbott, we have not included it in this review. One further reported case was mentioned by Abbott in 1937, and Curtis Bain and Parkinson (1943) have since recorded another. The chief findings in these 11 cases are summarized in Table $I$.

The average age at death was 14 years, but this approximate figure is much affected by two of the series who survived to 37 (Girard, 1895) and 48 (Moorhead and Smith, 1922) years respectively, and in both of whom the septal defect was small. Three dying in early infancy (Gerhardt, 1874; Rauchfuss, 1878; Hektoen, 1901) are not fully described; and two (Baginsky, 1879; Cæsar, 1880) died respectively in childhood from convulsions during whooping cough and from brain abscess and tuberculous meningitis. Excluding all these, it is still evident, however, that the defect is a serious threat to life, for only one of the five remaining cases, including our own, survived beyond the second decade. Indeed, the most remarkable feature of our case was his survival until adolescence despite such a gross defect $-a$ feature shared with the example reported by Bain and Parkinson (1943).

Though survival is variable, the physical limitations that the defect imposes appear to be almost uniform and always considerable. Symptoms of cardiac insufficiency from early infancy are always recorded where details are given, with one exception (Moorhead and Smith, 1922). This exception was a man of 48 , fit until 9 months before his death when symptoms began suddenly with severe chest pain and dyspnœa. Although the sudden onset, rapid course and previous good health suggested an acquired condition, the absence of disease in the aortic wall compelled the authors to regard the defect as congenital. With the two exceptions already noted (Baginsky, 1879; Cæsar, 1880) and another three for whom the cause of death was not stated, all the others died with congestive heart failure. There is no record of endocarditis as a complication; and the only mention of clubbing is by Cæsar (1880) and Bain and Parkinson (1943) who noted its moderate degree. In both these clinical points there is a similarity to atrial septal defect (Bedford, Papp, and Parkinson, 1941).

The cardiac murmurs vary greatly. Cæsar (1880) specifically noted the absence of murmurs; and both Wilks (1859) and Girard (1895) mentioned only a loud systolic murmur over the base of the heart. Fräntzel (1868), Baginsky (1879), and Moorhead and Smith (1922) all described a double murmur. A loud apical diastolic murmur alone, with a thrill, was noted by Bain and Parkinson (1943). It is evident that basically the signs are similar to those of any other free leakage from the aorta above the cusps as with a patent ductus, a ruptured aneurysm of a sinus of Valsalva, and an acquired communication between the aorta and pulmonary artery. Abbott (1937) suggested that diastolic accentuation might be due to secondary pulmonary insufficiency. Although a functional incompetency may well have been present in our case, none could be demonstrated at necropsy. Abbott also noted that the double murmur seemed to be more superficial than that of a patent ductus, an observation that we can confirm. As in our case, Moorhead and Smith (1922) found a large pulse pressure; the only other record (Bain and Parkinson 1943) failed to show it.

The heart is always much enlarged. Dilatation and hypertrophy affect both ventricles, the right one especially. Aneurysmal dilatation of the pulmonary artery, by far the most impressive finding in our case, is by no means constant, a fact no doubt related to the frequency of small defects. Wilks (1859) drew attention, however, to the importance of pulmonary artery dilatation in his own case; and Bain and Parkinson (1943) found the pulmonary artery forming about two-thirds of the aneurysmal sac.

The site of the defect is remarkably constant and the lower border is formed by a smooth ridge of tissue separating the aortic and pulmonary sinuses. Though variable in size, the defect is generally small, about $1 \mathrm{~cm}$. in diameter. In our own case it was $6 \mathrm{~cm} . \times 5 \mathrm{~cm}$., and, as in that of Bain and Parkinson (1943), was quite exceptional. The fine smooth edges are characteristic and distinguish the congenital from the commoner acquired communication between aorta and pulmonary artery (Brocq, 1885 and 1886). Moreover, acquired defects are accompanied by aortic disease, commonly a ruptured aneurysm of the ascending aorta (Porter, 1942).

Judging from the few records, other congenital cardiovascular defects are usually absent. Fräntzel (1868) found the pulmonary artery distributed to the - left lung only, the right pulmonary artery springing from the ascending aorta. Hektoen's case (1901), 


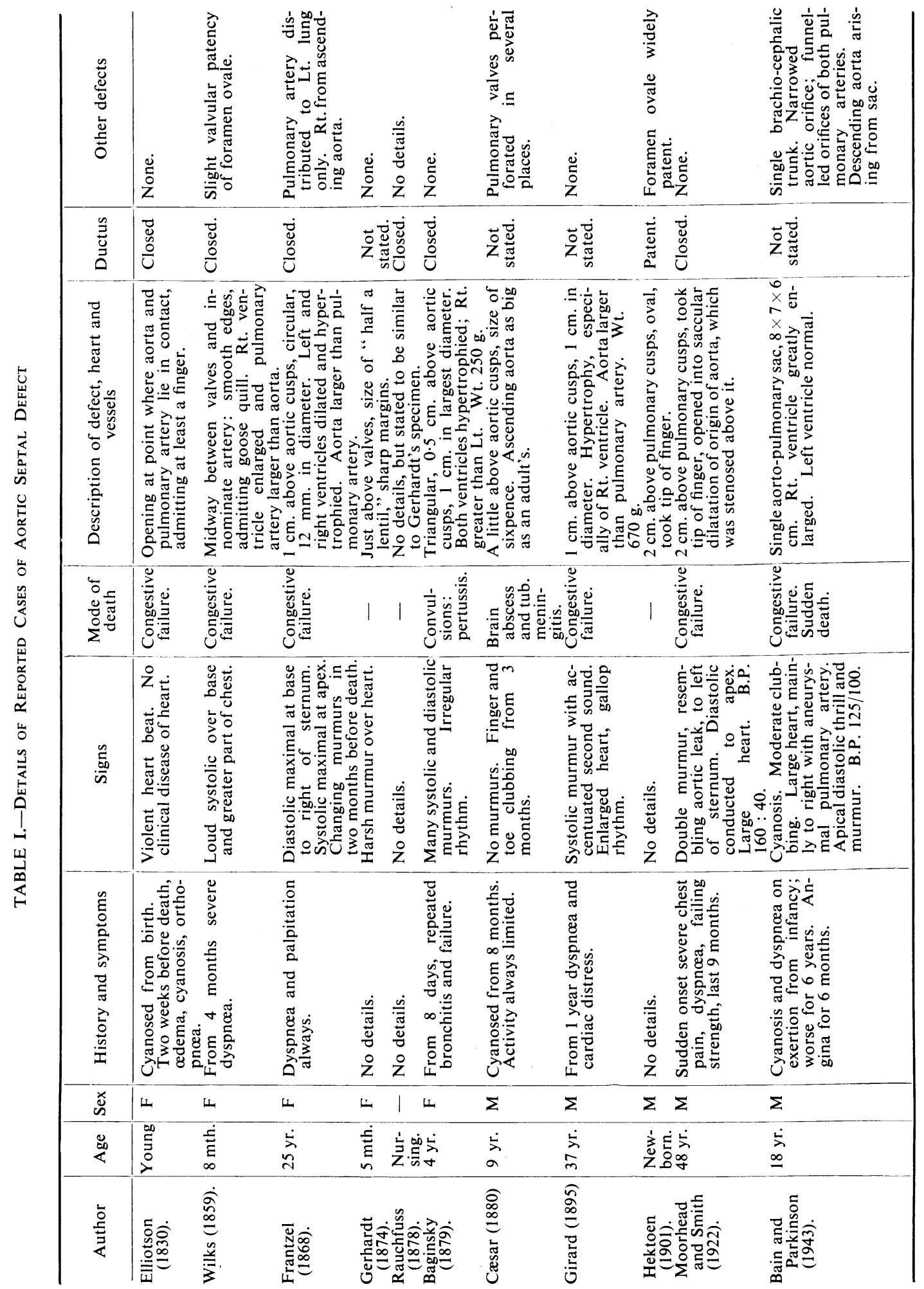


dying at birth, had a patent ductus and widely patent foramen ovale; and Wilks' case (1859) at eight months also had a slight valvular patency of the foramen ovale. Cæsar (1880) found the pulmonary valves perforated in several places. Bain and Parkinson (1943) found a common brachiocephalic trunk and funnelled openings from the sac into each main branch of the pulmonary artery. Apart from these few, the aortic septal defect has been the sole congenital abnormality in all the recorded examples. In contrast to this rarity of other defects, the communication produced by rupture of the right sinus of Valsalva into the conus is generally accompanied by a defect in the membranous part of the septum.

\section{Diagnosis}

The clinical recognition of congenital patency of the aortic septum is necessarily difficult, if only because of its rarity. In none of the recorded cases was the diagnosis made in life; and it is doubtful how far it has, in fact, been considered hitherto. Certainly in our own case it was not. We believed we were dealing with a complicated defect, including a patent ductus arteriosus and probably an atrial septal defect, a combined condition that has been reported and has been diagnosed during life.

The question remains whether a pure aortic septal defect can be recognized in life. Acquired defects are not uncommonly recognized (Porter, 1942; Schattenberg and Harris, 1943). Primarily the diagnosis depends upon signs of a free leak from the aorta in the presence of a dilated pulmonary arterial tree and enlargement of both ventricles. Such a combination is rare enough if we except patent ductus arteriosus either alone or along with an atrial septal defect. When a patent ductus is the sole abnormality, enlargement of the heart and of the pulmonary artery and its branches is rarely so striking as that found with the large aortic septal defects in Bain and Parkinson's case and in our own. As, however, the defect is often small, the same degree of enlargement is not always found.

The difference from a patent ductus would then be much less obvious, and a distinction have to rest with the more superficial murmur. When a patent ductus has anomalous signs, even no murmur, yet an unusually large pulmonary artery and branches, the difficulties in recognition may well be insuperable. The injection of contrast media by the basilic vein is unlikely to provide conclusive evidence regarding the exact site of the aortopulmonary leak because dilution in the pulmonary artery by the aortic blood would make radiographic interpretation so difficult. Perhaps in future retrograde angiocardiography may resolve the difficulty. It is said to outline a patent ductus very clearly, and would almost certainly show the site and size of an aortic septal defect.

Atrial septal defect alone, however, should be distinguishable, for here the auscultatory signs, though they may suggest an aortic leak, are not accompanied by excessive pulsation in the aorta and its main branches, nor by an increased pulse pressure. Moreover, dyspnœa is late as a sypmtom, so late that a fair capacity for exertion is retained even with an enlarged heart well into middle life, a further contrast with aortic septal defect. Also congestive failure is not found before the third decade of life, nor is the left ventricle characteristically involved in the cardiac enlargement. Atrial septal defects also give characteristic findings on right heart catheterization (Howart, McMichael, and SharpeySchafer, 1947).

If an atrial septal defect is accompanied by a patent ductus the similarity to a widely patent aortic septum is much more striking, especially in the degree of enlargement of right ventricle and pulmonary arteries. But here again catheterization might be expected to reveal the atrial defect and suggest this combination from the associated physical signs.

In so far as there is a common arterial sac with which both ventricles communicate, it might be expected that a persistent truncus arteriosus would most closely resemble a wide patency of the aortic septum; and yet, to judge from the records, this is not necessarily so. There is general agreement on the poor prognosis of a truncus, the presence of a systolic murmur and thrill along with much enlargement of both ventricles, and a broad vascular pedicle. But with a truncus, cyanosis is usually early and marked, although Taussig (1947) has recently claimed that this is the case only when the pulmonary circulation is maintained largely through the bronchial arteries The main pulmonary arteries are then either absent or rudimentary, and the radiological counterparts are the finding of small and ill-defined hilar shadows, a concave upper margin of the left border of the heart, and a hazy margin of the aortic arch due to the abnormally large superior bronchial arteries arising from it (Taussig, 1947). These points might clearly help to separate a truncus case of this type from a simple aortic septal defect, though in her recent book Taussig (1947) makes no reference to the latter.

We also have to consider in differential diagnosis joint aortic and pulmonary valvular disease, aneurysm of a sinus of Valsalva, and an acquired as distinct from a congenital aortic septal defect. None of these is likely to be traced to early child- 
hood by the symptoms and they all have the marks of acquired disease-rheumatic, syphilitic, or bacterial. An acquired aortic septal defect has a sudden, even dramatic, onset and runs a rapid course, commonly as a complication of an existing aortic aneurysm or, more rarely, of bacterial endarteritis. Evidence of an infection is in each condition more important as a guide than the details of cardiac enlargement or the nature of any murmurs. Combined enlargement of right and left ventricles, pulmonary arteries, and aortic root may be present in all of them as well as in congenital aortic septal defect; and along with this a double basal murmur, increased pulsation in the aorta and its branches, and an increased pulse pressure.
Separation from congenital aortic septal defect may be feasible only if the probability of an acquired lesion in a subject past youth is integrated with collateral evidence of an infective cause.

\section{Summary}

An example of congenital aortic septal defect is described together with radiological and necropsy findings.

Reported cases are reviewed and the diagnosis discussed.

We are greatly indebted to Sir John Parkinson, Dr. J. W. Brown and Dr. Frances Gardner for reading the manuscript and for their helpful criticisms.

\section{REFERENCES}

Abbott, M.E. (1919). Contributions to Medical and Biological Research, New York, 2, 899.

(1927). Osler and Macrae's Modern Medicine, 4, 710 .

(1937). Nelson's Loose Leaf Medicine, 4, 269.

Baginsky, B. (1879). Berl. klin. Wschr., 16, 439.

Bain, C. W. C., and Parkinson, J. (1943). Brit. Heart J., 5, 97.

Bedford, D. E., Papp, C., and Parkinson, J. (1941). Ibid., 3, 37.

Brocq, L. (1885). Rev. de Méd., 5, 1046.

- (1886). Ibid., 6, 786.

Brown, J. W. (1939). Congenital Heart Disease, London.

Cæsar, J. (1880). Lancet, 2, 768.

Elliotson, J. (1830-1831). Ibid., 1, 247.

Fräntzel, O. (1868). Virchows Arch., 43, 420.

Gerhardt, C. (1874). Lehrbuch der Kinderkrankheiten, $1,244$.
Girard, E. (1895). Zurich, Dissertation.

Goehring, C. (1920). J. med. Research, $42,49$.

Hektoen, L. (1901). Amer. J. med. Sci., 121, 163.

Howarth, S., McMichael, J., and Sharpey-Schafer, E. P. (1947). Brit. Heart J., 9, 292.

Macleod, A. (1944). Ibid., 6, 194.

Moorhead, T. G., and Smith, E. C. (1922). Irish Journ. med. Sci., 5th Series, 1, 545.

Porter, W. B. (1942). Amer. Heart J., 23, 468.

Rauchfuss, C. (1878). In Gerhardt, C., Handbuch der Kinderkrankheiten, 4, footnote 61 .

Rickards, E. (1881). Brit. med. J., 2, 71.

Schattenberg, H. J., and Harris, W. H. (1943). Amer. Heart J., 25, 512.

Taussig, H. B. (1947). Congenital Malformations of the Heart, New York.

Wilks, S. (1859-60). Trans. Path. Soc., London, 11, 57. 